\title{
Extracorporeal membrane oxygenation for respiratory failure in COVID-19 patients: outcome and time-course of clinical and biological parameters
}

\author{
Pierre Huette, MD 1 - Christophe Beyls, MD • Mathieu Guilbart, MD • \\ Alexandre Coquet, MD • Pascal Berna, MD, PhD • Guillaume Haye, MD • \\ Pierre-Alexandre Roger, MD • Patricia Besserve, MD • Michael Bernasinski, MD • \\ Hervé Dupont, MD, PhD • Osama Abou-Arab, MD, PhD • Yazine Mahjoub, MD, \\ PhD
}

Received: 24 April 2020/Revised: 23 May 2020/Accepted: 25 May 2020/Published online: 1 June 2020

(c) Canadian Anesthesiologists' Society 2020

\section{To the Editor,}

The place of extracorporeal membrane oxygenation (ECMO) therapy in the coronavirus disease 2019 (COVID19) outbreak is undefined. ${ }^{1}$ Our tertiary hospital is situated in Picardy (northern France), one of the areas most affected by the outbreak in France. We report a prospective caseseries that describes the clinical course of patients with COVID-19 with respiratory failure requiring veno-venous ECMO between March 2020 and April 2020.

After ethical approval, we prospectively collected data on consecutive COVID-19 patients (confirmed with reverse transcription polymerase chain reaction testing) admitted to our referral centre for ECMO therapy. Demographic, biological, and clinical data were collected during ECMO therapy. Data on outcomes were reported. Fourteen patients were eligible for ECMO during this period; two of them died in peripheral centres during ECMO cannulation (one patient was in refractory septic shock and one patient had a massive pulmonary embolism). Twelve patients were admitted to our centre; all had

Electronic supplementary material The online version of this article (https://doi.org/10.1007/s12630-020-01727-z) contains supplementary material, which is available to authorized users.

P. Huette, MD $(\bowtie) \cdot$ C. Beyls, MD - M. Guilbart, MD .

A. Coquet, MD - G. Haye, MD - P.-A. Roger, MD .

P. Besserve, MD - M. Bernasinski, MD .

H. Dupont, MD, PhD - O. Abou-Arab, MD, PhD .

Y. Mahjoub, MD, PhD

Department of Anesthesiology and Critical Care Medicine,

Amiens University Hospital, Amiens, France

e-mail: huette.pierre@chu-amiens.fr

P. Berna, MD, PhD

Department of Thoracic Surgery, Amiens University Hospital,

Amiens, France percutaneous femoro-jugular cannulation. Patients were mainly male with a medical history of hypertension and diabetes (eTable 1 in the Electronic Supplementary Material [ESM]). Prior to ECMO, patients were severely hypoxemic with a median [interquartile range (IQR)] arterial oxygen partial pressure/fractional inspired oxygen $\left(\mathrm{PaO}_{2} / \mathrm{F}_{\mathrm{I}} \mathrm{O}_{2}\right)$ ratio of 76 [66-83] mmHg, $\mathrm{pH}$ of 7.31 [7.227.36], and partial pressure of carbon dioxide of 55 [42-60] $\mathrm{mmHg}$. In line with current data, we found a mildly impaired respiratory system compliance of 30 [27-32] $\mathrm{mL} \cdot \mathrm{mmHg}^{-12}$ All patients were treated with inhaled nitric oxide, neuromuscular blockade, and prone positioning prior to ECMO therapy. Median [IQR] intensive care unit (ICU) length of stay before ECMO initiation was 6 [4-8] days. Median [IQR] lymphocyte count was 600 [400-1000] $\mathrm{mm}^{-3}$, fibrinogen 7.5 [5.1-9] $\mathrm{g} \cdot \mathrm{L}^{-1}$, and C-reactive protein 257 [181-295] $\mathrm{mg} \cdot \mathrm{L}^{-1}$ (eTable 2 as ESM).

Ten (83\%) patients were weaned from ECMO and two patients died under ECMO. Duration of ECMO therapy was 12 [9-22] days. Nine patients (75\%) were weaned from mechanical ventilation. Overall, eight patients $(67 \%)$ were discharged from the ICU and four (33\%) died (Figure). Lung-protective ventilation was maintained during ECMO. Duration of mechanical ventilation was 25 [19-30] days and ten (83\%) patients developed ventilator associated pneumonia (VAP). All patients received heparin treatment for an anti-Xa level target of $0.2-0.3$ UI $\cdot \mathrm{mL}^{-1}$. Thrombotic events occurred in $11(92 \%)$ patients: deep vein thrombosis (four patients), renal replacement therapy (RRT) circuit clotting (two patients), complete clotting of the ECMO circuit (three patients), and pulmonary embolism (two patients). Eleven (92\%) patients had Kidney Disease: Improvement of Global Outcomes 2 or 3 classification of acute kidney injury (AKI) and eight (67\%) required RRT (eTable 3 as ESM). 


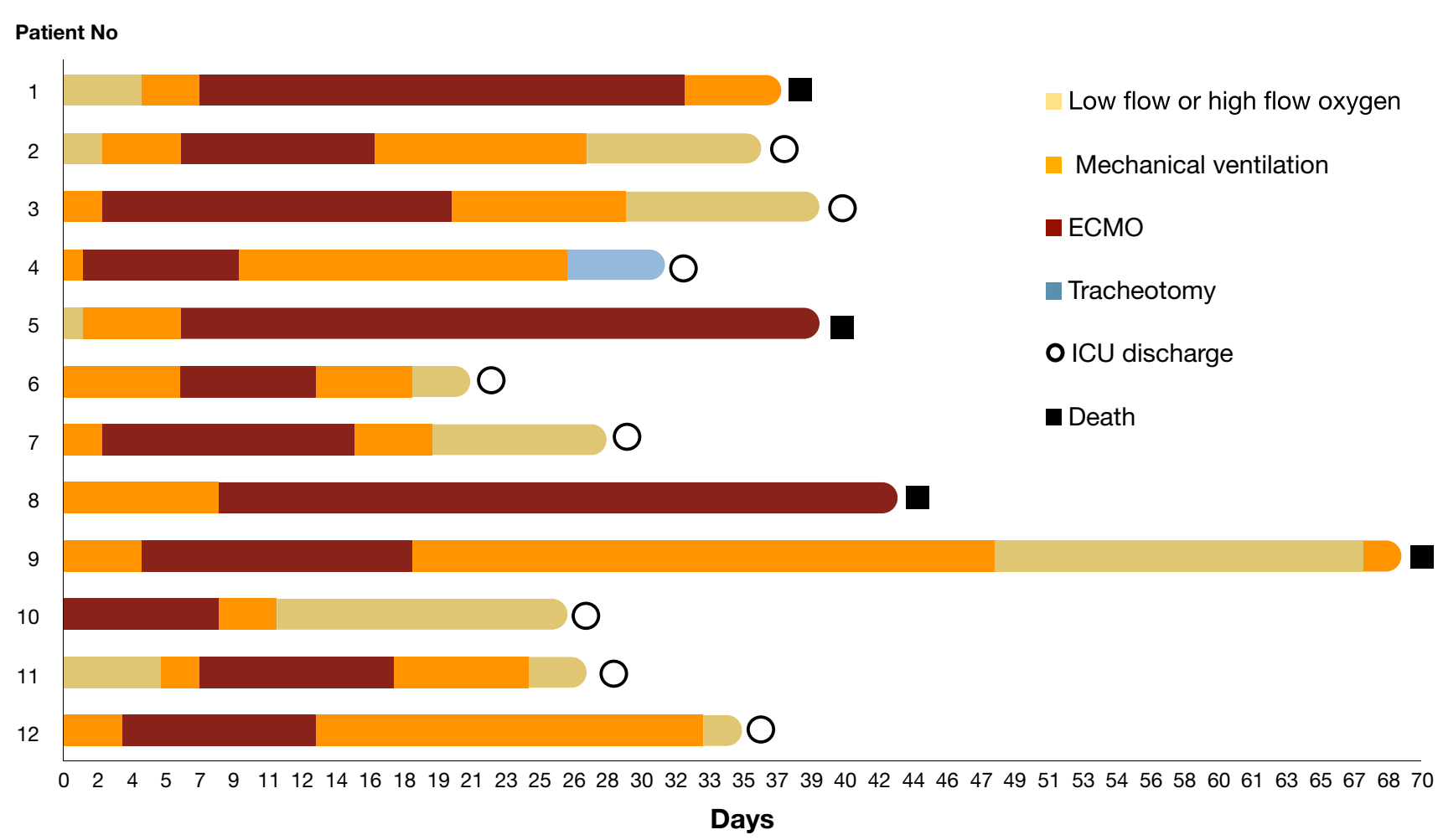

Figure ECMO course for COVID-19 patients. COVID-19 = coronavirus disease 2019; ECMO = extracorporeal membrane oxygenation.

For patients weaned from ECMO, biological data showed an increase in lymphocyte count (from 560 [401927] $\mathrm{mm}^{-3}$ to $1,280[745-1,494] \mathrm{mm}^{-3}$ ) and a decrease in fibrinogen (from $6.8[5.1-8] \mathrm{g} \cdot \mathrm{L}^{-1}$ to $3.6[3.2-5.0] \mathrm{g} \cdot \mathrm{L}^{-1}$ ). We observed an increase in $\mathrm{PaO}_{2} / \mathrm{F}_{1} \mathrm{O}_{2}$ ratio from 129 [104-210] mmHg to 268 [213-340] mmHg, and an initial decrease in respiratory compliance from 29.3 [26.7-30] to $19.3[17.6-20] \mathrm{mL} \cdot \mathrm{mmHg}^{-1}$, followed by an increase to 26.8 [25.4-27.1] $\mathrm{mL} \cdot \mathrm{mmHg}^{-1}$ (eFigure as ESM).

In this case-series of patients with COVID-19-related respiratory failure, we found a high rate of ECMOweaning. Complications such as AKI, thrombosis, and VAP occurred frequently. A high risk of thrombosis for COVID-19 patients under ECMO has been suggested previously. ${ }^{3}$ At the initiation of ECMO, patients had low lymphocyte counts that increased progressively until weaning, in accordance with previous reports showing that most severe COVID-19 cases had persistently low lymphocyte counts. ${ }^{4}$ In our experience, a reduction in fibrinogen correlates with improvements in oxygenation. Decreasing fibrinogen levels may be a marker for improvement in the coagulopathy and a reduction in disease severity, with improvement in oxygenation. ${ }^{5}$ Studies with a larger sample size are needed to draw formal conclusions about the benefit of ECMO therapy for COVID-19-related respiratory failure.

Disclosures None.

Funding statement None.

Editorial responsibility This submission was handled by Dr. Sangeeta Mehta, Associate Editor, Canadian Journal of Anesthesia.

\section{References}

1. Ramanathan $K$, Antognini D, Combes A, et al. Planning and provision of ECMO services for severe ARDS during the COVID19 pandemic and other outbreaks of emerging infectious diseases. Lancet Respir Med 2020; DOI: https://doi.org/10.1016/S22132600(20)30121-1.

2. Gattinoni L, Coppola S, Cressoni M, Busana M, Rossi S, Chiumello D. Covid-19 does not lead to a "typical" acute respiratory distress syndrome. Am J Respir Crit Care Med 2020; DOI: https://doi.org/10.1164/rccm.202003-0817LE.

3. Beyls C, Huette $P$, Abou-Arab O, Berna P, Mahjoub Y. Extracorporeal membrane oxygenation for COVID-19-associated severe acute respiratory distress syndrome and risk of thrombosis. 
Br J Anaesth 2020; DOI: https://doi.org/10.1016/j.bja.2020.04. 079 .

4. Wang D, Ни В, Ни C, Characteristics Clinical, et al. Clinical Characteristics of 138 hospitalized patients with 2019 novel coronavirus-infected pneumonia in Wuhan, China. JAMA 2020; DOI: https://doi.org/10.1001/jama.2020.1585.

5. Helms J, Tacquard $C$, Severac F, et al. High risk of thrombosis in patients in severe SARS-CoV-2 infection: a multicenter prospective cohort study. Intensive Care Med 2020; DOI: https:// doi.org/10.1007/s00134-020-06062-x.

Publisher's Note Springer Nature remains neutral with regard to jurisdictional claims in published maps and institutional affiliations. 